\title{
Species diversification in the Mediterranean genus Chiliadenus (Inuleae-Asteraceae)
}

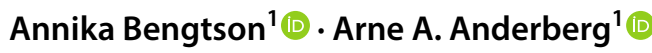

Received: 12 October 2017 / Accepted: 22 April 2018 / Published online: 10 May 2018

(c) The Author(s) 2018

\begin{abstract}
Chiliadenus is a small genus in the Inuleae (Asteraceae), consisting of ten species with allopatric distributions along the southern edge of the Mediterranean Sea. The different species have restricted areas of distribution, with only one being more widely distributed. The first molecular phylogenetic study of the genus with complete sampling, as well as a biogeographic analysis of the origin and biogeographic patterns leading to the current diversity of Chiliadenus is presented. Results confirm Chiliadenus as monophyletic and placed as sister to Dittrichia. The ancestor of Chiliadenus is dated to have diverged from that of Dittrichia around 5.45 Ma ago, coinciding with the Messinian salinity crisis, whereas the Chiliadenus crown group is dated to $2.29 \mathrm{Ma}$, around 3 million years later. Ancestral area reconstructions show the crown group to likely have originated in the area around Morocco and northwestern Algeria, which is also the area where the early divergences have occurred. Chiliadenus has then later diverged and dispersed over the Mediterranean to its current distribution. The evolution of the Chiliadenus crown group coincides with the onset of the Mediterranean climate, and its evolution may be connected to the subsequent climatic changes.
\end{abstract}

Keywords Asteraceae $\cdot$ Biogeography $\cdot$ Chiliadenus $\cdot$ Inuleae $\cdot$ Mediterranean

\section{Introduction}

The Mediterranean basin is well known for its high plant diversity and its high level of endemism. The flora comprises around 24-25.000 plant species, up to around 60\% of which are endemic to the area (Greuter 1991). The high diversity has often been explained by a combination of the heterogeneous landscape and the results of important geological events, climatic oscillations, the complex geography, and topography of the area (Thompson 2005; Bonanno and Veneziano 2016). However, much remains unknown, and studies of the taxa that together make up the Mediterranean flora are therefore of great interest.

Handling editor: Christoph Oberprieler.

Electronic supplementary material The online version of this article (https://doi.org/10.1007/s00606-018-1515-2) contains supplementary material, which is available to authorized users.

Annika Bengtson

annika.bengtson@nrm.se

1 Department of Botany, Swedish Museum of Natural History, P.O. Box 50007, 10405 Stockholm, Sweden
One representative of the Mediterranean flora is Chiliadenus Cass., a small genus of ten species of the Inuleae-Inulineae of the daisy family (Asteraceae), consisting of woody perennial herbs or shrublets with (mostly) discoid heads and yellow flowers (Fig. 1) (Englund et al. 2009; Anderberg 2012; Nylinder and Anderberg 2015). The species of the genus have often been treated as members of Jasonia Cass. and/or Varthemia DC. in floras, but were moved into the genus Chiliadenus by Brullo (1979) based on morphology. Phylogenetic analyses (Englund et al. 2009; Nylinder and Anderberg 2015) have shown that Chiliadenus is not related to Varthemia, and that its sister group is the widely distributed and often weedy genus Dittrichia Greuter.

The Chiliadenus species are predominantly distributed along the southern edge of the Mediterranean Sea, with one species extending into continental southwestern Europe. All species grow in rocky environments, and only Chiliadenus saxatilis has a wider distribution (Fig. 2) (Brullo 1979; Gómiz 2000). All ten Chiliadenus species have allopatric distributions around the Mediterranean basin; Chiliadenus antiatlanticus (Emb. \& Maire) Gómiz (northern Morocco), C. bocconei Brullo (Malta), C. candicans (Delile) Brullo (northeastern Libya, northwestern Egypt), C. hesperius 


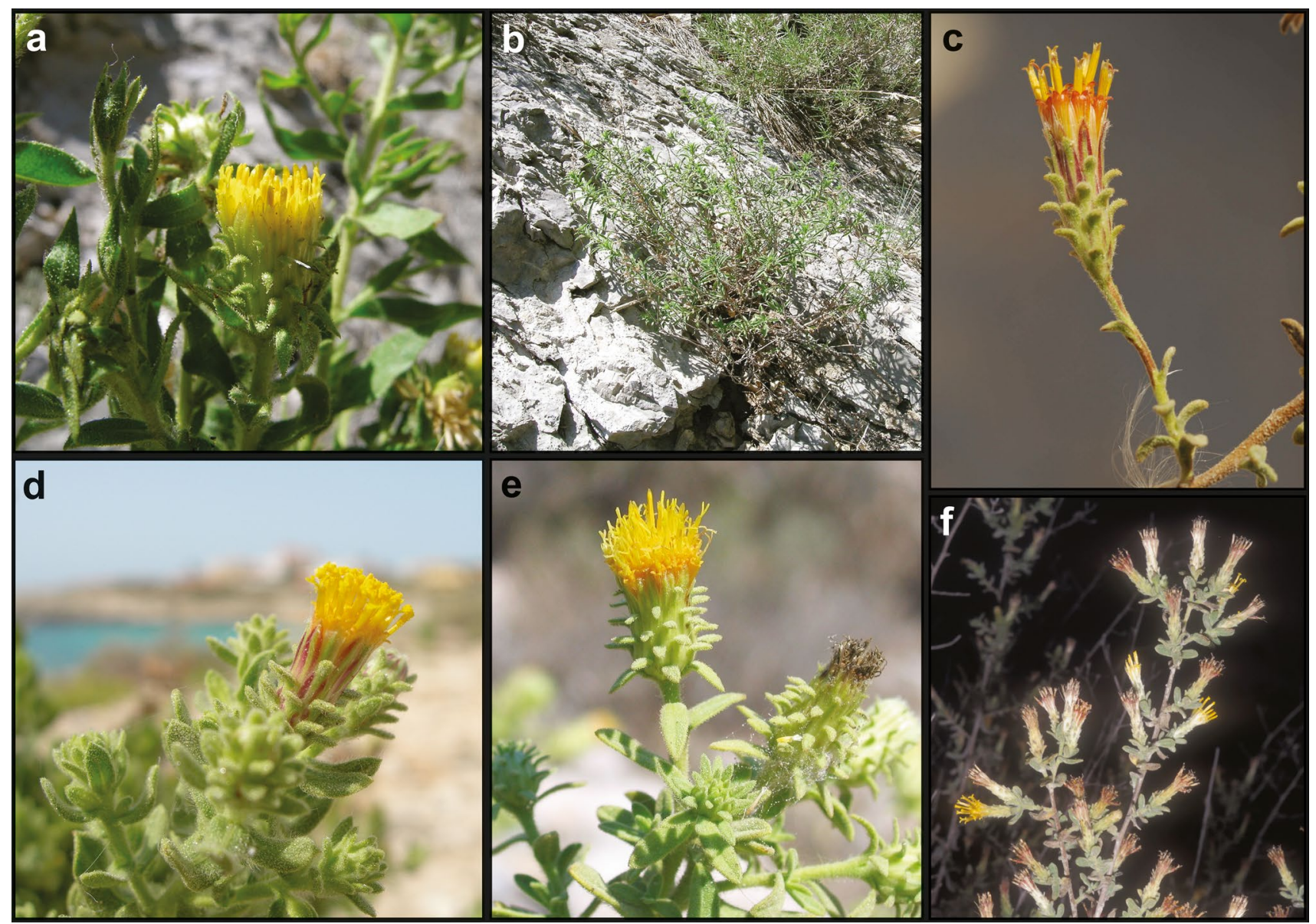

Fig. 1 a, b Chiliadenus saxatilis, photos by M. Englund; c C. montanus, photo by O. Fragman-Sapir; d C. lopadusanus, photo by R. Anderberg; e C. bocconei, photo by S. Mifsud; f C. iphionoides, photo by O. Fragman-Sapir

(Maire \& Wilczek) Brullo (southern Morocco), C. lopadusanus Brullo (Italy; Lampedusa island), C. iphionoides (Boiss $\&$ C.I.Blanche) Brullo (Israel, Egypt; Sinai, Lebanon), $C$. montanus (Vahl) Brullo (Egypt; Sinai, Jordan), C. rupestris (Pomel) Brullo (northeastern Morocco, northwestern Algeria), C. saxatilis (Lam.) Brullo (Spain, France, northern Morocco) and C. sericeus (Batt. \& Trab.) Brullo (Algeria; central Sahara) (Fig. 2). The different Chiliadenus species all have restricted areas of distribution, with some being limited to very small areas, something that made Brullo (1979) hypothesize a pre-Quaternary origin for the group. The current distribution pattern of Chiliadenus, mainly consisting of local endemics, with only a few more widespread species, and all with distributions around the Mediterranean basin could be the result of fragmentation and geographic isolation of a once widespread ancestor. An alternative explanation would be dispersal across the sea and to the relatively isolated habitats now inhabited by the present day species.

The age and biogeographical origin of the genus Chiliadenus has never been studied, and whether its current diversity and distribution is the result of fragmentation from a once widespread ancestor or from dispersal is therefore unknown. The aim of the study is to produce a dated species phylogeny and to analyze the biogeographic patterns resulting in the current diversity and distribution of Chiliadenus.

\section{Materials and methods}

\section{Taxon sampling}

All ten Chiliadenus species were included in the study, with several representatives of all taxa except from $C$. sericeus where only few herbarium specimens were found, selected to cover the geographic range of the species. Outgroup taxa were selected based on earlier studies of Inuleae (Englund et al. 2009; Nylinder and Anderberg 2015). Four plastid ( $n d h \mathrm{~F}, r p l 32-t r n \mathrm{~L}, t r n \mathrm{H}-p s b \mathrm{~A}$, and $t r n \mathrm{~L}-t r n \mathrm{~F}$ ) and two nuclear (ITS and ETS) regions were sequenced for the study. 124 new sequences were generated; the remaining sequences were obtained from GenBank. Geographical information on species distributions was taken from Brullo (1979) as well as 


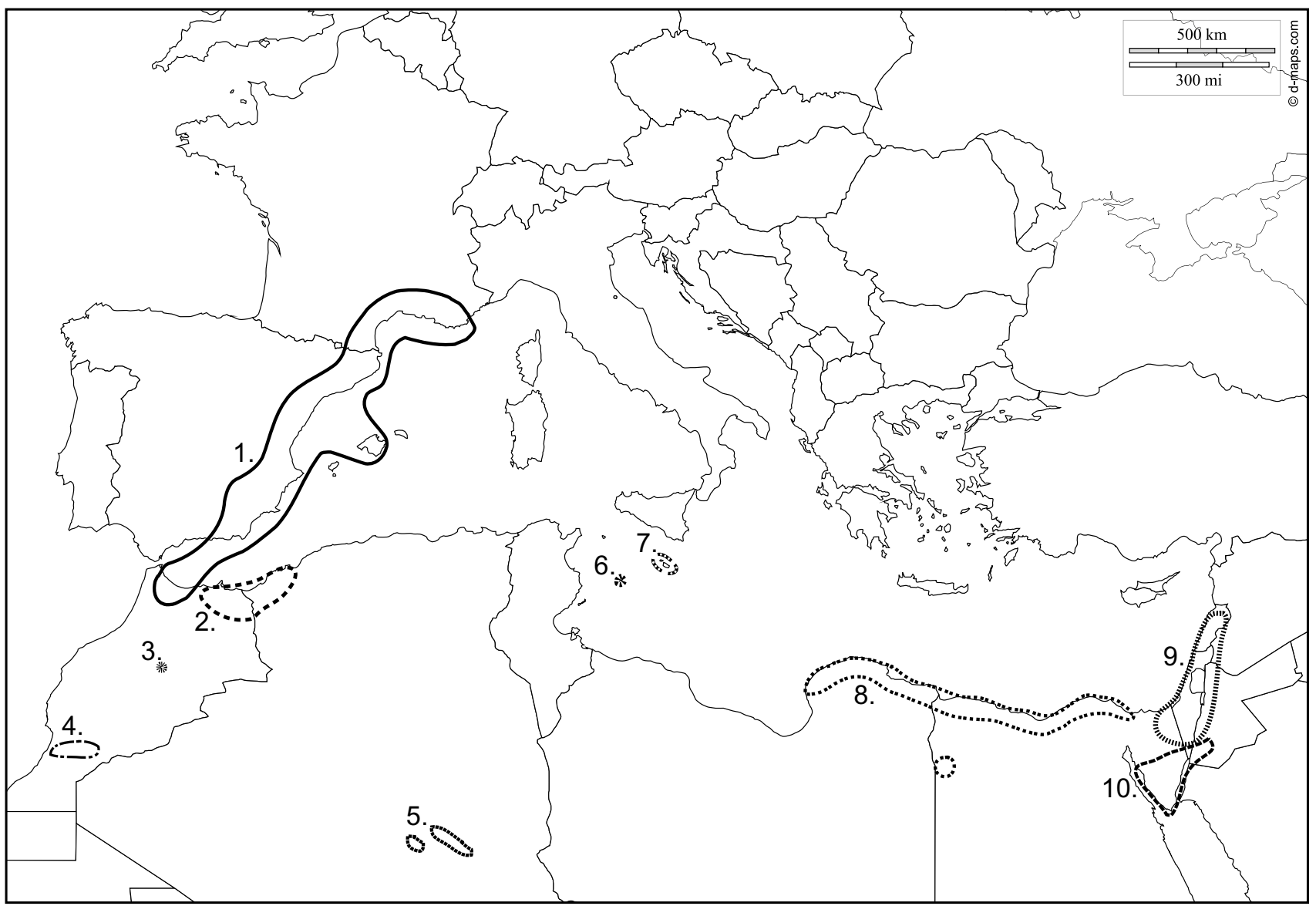

Fig. 2 Current distribution of Chiliadenus; 1 C. saxatilis, 2 C. rupestris, 3 C. antiatlanticus, 4 C. hesperius, 5 C. sericeus, 6 C. lopadusanus, 7 C. bocconei, 8 C. candicans, 9 C. iphionoides, 10 C. montanus. Map from http://www.d-maps.com

from herbarium specimens (from herbaria: BC, HUJ, MPU, $\mathrm{S}$, and $\mathrm{W}$ ). Voucher information and GenBank accession numbers for the taxa included in the molecular study are provided in Supplementary Material (Online Resource 1).

\section{DNA extraction, amplification, and sequencing}

DNA was extracted from herbarium material using a DNeasy Plant Mini Kit (Qiagen, Hilden, Germany) according to the manufacturer's instructions. The DNA regions of interest were amplified using Hot Start Mix RTG beads (GE Healthcare, Little Chalfront, UK) according to the standard protocol of the manufacturer. The internal transcribed spacer (ITS; including ITS1, ITS2 and the 5.8S gene) was amplified using primers 18SF, 26SR (Rydin et al. 2004), 5.8F-chrys (Howis et al. 2009) and 5.8SRPEny (Nylinder et al. 2013), and the external transcribed spacer (ETS) using primers Ast-1 (Markos and Baldwin 2001) and 18S-ETS (Baldwin and Markos 1998). The plastid $t r n \mathrm{~L}-t r n \mathrm{~F}$ region (including the $t r n \mathrm{~L}$ intron and $t r n \mathrm{~L}-t r n \mathrm{~F}$ intergenic spacer) was amplified using the "c", "d" "e" and "f" primers of
Taberlet et al. (1991), and the plastid trnH-psbA spacer using the trnH(GUG) and psbA-Lec primers of Hamilton (1999). The plastid $n d h \mathrm{~F}$ region was amplified using primers RJ1, RJ14 (Kim and Jansen 1995), ndhF16 (Källersjö et al. 2000), ndhF5 (Olmstead and Sweere 1994), 1750R-Ast2, 1650F-Ast (Nylinder et al. 2013), ndhF520R-Ast (Anderberg and Swenson 2003) and ndhF431F (Eldenäs et al. 1999), and the plastid $r p l 32-t r n \mathrm{~L}$ region using the primers of Shaw et al. (2007). A thermal profile of $95^{\circ} \mathrm{C} 5 \mathrm{~min},\left(95^{\circ} \mathrm{C} 30 \mathrm{~s}\right.$, $\left.54{ }^{\circ} \mathrm{C} 30 \mathrm{~s}, 72{ }^{\circ} \mathrm{C} 1 \mathrm{~min} 15 \mathrm{~s}\right) \times 4,\left(95^{\circ} \mathrm{C} 30 \mathrm{~s}, 53{ }^{\circ} \mathrm{C} 30 \mathrm{~s}\right.$, $\left.72{ }^{\circ} \mathrm{C} 1 \mathrm{~min} 15 \mathrm{~s}\right) \times 4,\left(95^{\circ} \mathrm{C} 30 \mathrm{~s}, 50^{\circ} \mathrm{C} 30 \mathrm{~s}, 72^{\circ} \mathrm{C} 1 \mathrm{~min}\right.$ $15 \mathrm{~s}) \times 35,72{ }^{\circ} \mathrm{C} 8 \mathrm{~min}$ was used for amplification of all regions. Amplified products were purified using one portion of Exonuclease I $(20 \mathrm{u} / \mu \mathrm{l})$ and four portions FastAPTM Thermosensitive Alkaline Phosphatase $(1 \mathrm{u} / \mu \mathrm{l}$; Thermo Scientific, Lithuania). Sequencing reactions were performed using an ABI BigDye Terminator Kit v. 3.1 (Applied Biosystems, Warrington, UK) according to the manufacturer's instructions. The products were cleaned using a DyeEx ${ }^{\circledR} 96$ Kit (Qiagen, Hilden, Germany), and analyzed on an ABI3130xl automated sequencer. Sequences were assembled and edited 
using the Staden package (Staden 1996), aligned using MUSCLE (Edgar 2004) as implemented in Aliview v. 1.17.1 (Larsson 2014) and manually edited using BioEdit v. 7.2.5 (Hall 1999). Individual loci were model tested for the best fitting substitution model using jModeltest v. 2.1.5 (Darriba et al. 2012) under the Akaike information criterion (AIC; Akaike 1973).

\section{Molecular age estimation and ancestral area reconstructions}

Prior to combining the individual loci of the dataset, separate Bayesian inference analyses were conducted (using MrBayes, v. 3.2.2; Huelsenbeck and Ronquist 2001) of each marker to check for incongruence. Divergence times and ancestral areas were estimated using BEAST v. 1.8.0 (Drummond et al. 2012), using the online XSEDE platform on the CIPRES Science Gateway (https://www.phylo.org/porta 12/). The dataset was partitioned according to the six separate markers, substitution models and molecular clock rates were unlinked for all partitions except for the plastid regions ( $n d h \mathrm{~F}, r p l 32-t r n \mathrm{~L}, t r n \mathrm{H}-p s b \mathrm{~A}$ and $t r n \mathrm{~L}-t r n \mathrm{~F})$ which were treated as a united supergene. Substitution models were set to TIM3ef $+\Gamma$ for ITS, HKY $+\Gamma$ for ETS, and TPM 3 uf $+\Gamma$ for the plastid markers, suggested as best fit for the data by the model tests. Speciation was modeled by a birth/death prior (Gernhard 2008). Substitution rates were assigned exponential decays with the mean 0.1 (substitutions/site/time unit) to suggest vague but reasonable assumptions on the limits of rate distributions and avoid using uninformative priors. All other priors were left unconstrained. Due to a lack of fossil evidence relating to Inuleae, we have used ITS substitution rates from previously published studies (Schmidt and Schilling 2000; Kay et al. 2006; Lancaster 2010) for calibration purposes. ITS substitution rate estimates derived from three different Asteraceae representatives (Artemisia L., $1.69 \times$ $10^{-9}$, Ericameria Nutt., $2.17 \times 10^{-9}$, Eupatorium L. 2.51 $\times 10^{-9}$ ) with a life span similar to that of Chiliadenus were utilized. The calibration was modeled by a normal distribution using the published rates as mean with a $95 \%$ credibility interval corresponding to the full uncertainty of the three rates, following Nylinder et al. (2014).

Ancestral areas were reconstructed using the discrete phylogeographical trait implementation in BEAST, integrating over the uncertainty of the tree topology as well as the trait model. The distribution of Chiliadenus was divided into five areas, and the different species coded according to distribution (Figs. 2, 3). Species with a wide distribution were coded as multistate. A reversible rate matrix assigned equal prior probabilities for transitions between any two areas (continental southwestern Europe, Morocco and northwestern Algeria, Algeria (central Sahara), south Mediterranean islands
(Malta and Lampedusa), and the eastern Mediterranean region; see Fig. 3).

Analyses were performed using a Markov chain Monte Carlo (MCMC) and were run three times for 80 million generations each, logging parameters every 8000 generations. All runs were initiated on random starting trees. Convergence and mixing of Markov chains and effective sample size (ESS) values for all parameters were checked using Tracer v. 1.5 (Rambaut and Drummond 2009). The posterior distributions of trees were summarized using TreeAnnotator v. 1.8.0 (Drummond et al. 2012), removing a proportion of each run as burn-in, and visualized using FigTree v. 1.3.1 (Rambaut 2009).

\section{Results}

The dataset consisted of 5897 aligned nucleotide characters, 174 of which were informative. A description of the dataset is given in Table 1. No signs of incongruences were detected when analyzing the separate markers independently.

The dated BEAST MCC tree, including ancestral area reconstructions, is shown in Fig. 3. Our analyses confirm the genus Chiliadenus as monophyletic ( $\mathrm{PP}=1.0$; Fig. 3$)$ and placed as sister to Dittrichia ( $\mathrm{PP}=1.0$; Fig. 3). Chiliadenus is estimated to have diverged from Dittrichia around 5.45 Ma (95\% HPD 3.25-8.55 Ma; Fig. 3, node 1), with continental southwestern Europe (area A, see Fig. 3), Morocco and northwestern Algeria (B) estimated as the most probable ancestral area [with a posterior probability (pp) of 0.43 for A, 0.26 for B]. The crown age of Chiliadenus is in our analyses estimated to $2.29 \mathrm{Ma}(1.37-3.58 \mathrm{Ma})$, and ancestral area reconstructions show Morocco and northwestern Algeria (B) as most probable ancestral area ( $\mathrm{pp}=0.67$; Fig. 3, node 2). The phylogenetic relationships of the different species within Chiliadenus are resolved (Fig. 3). A clade consisting of Chiliadenus saxatilis, $C$. sericeus, and $C$. antiatlanticus $(\mathrm{PP}=1.0$; Fig. 3, node 3), with current distributions in continental southwestern Europe, Morocco and Algeria, respectively, is estimated to $1.03 \mathrm{Ma}(0.42-1.91 \mathrm{Ma})$. Morocco and northwestern Algeria (B) is estimated as the most probable ancestral area $(\mathrm{pp}=0.7$; Fig. 3 , node 3$)$. The crown age of the rest of Chiliadenus is estimated to $1.96 \mathrm{Ma}$ (1.15-3.04 Ma), with Morocco and northwestern Algeria (B) as most probable ancestral area $(\mathrm{pp}=0.69$; Fig. 3 , node 4$)$. Chiliadenus bocconei and C. lopadusanus, with distributions of Malta and Lampedusa, respectively, are shown to be sisters ( $\mathrm{PP}=1.0$; Fig. 3, node 7), with the south Mediterranean islands (D) as most probable ancestral area $(\mathrm{pp}=0.89$; Fig. 3, node 7). Their stem node is estimated to have diverged from the eastern Mediterranean clade (consisting of Chiliadenus candicans, C. montanus and C. iphionoides) around 1.58 Ma (0.9-2.49 Ma; Fig. 3, node 5), and ancestral 


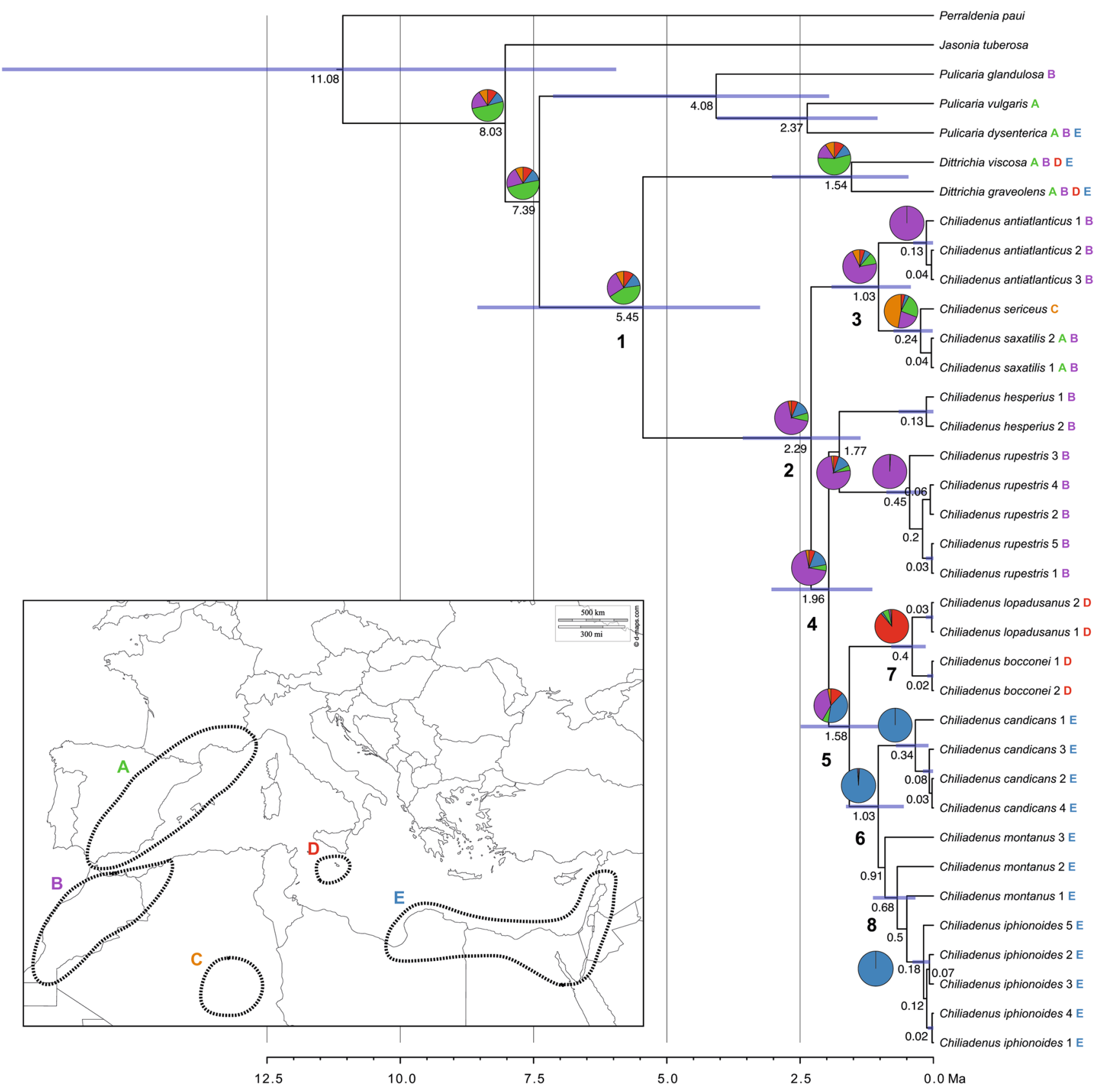

Fig. 3 Maximum clade credibility (MCC) tree with median node ages for Chiliadenus. Strongly supported nodes (posterior values $\geq 0.95$ ) are presented with node bars, representing the $95 \%$ highest posterior density (HPD) intervals. Relative probabilities of ancestral areas for selected nodes are shown as pie charts. Extant distributions are indicated after the taxon names. Map showing areas used in ancestral area reconstructions (A continental southwestern Europe, B Morocco and northwestern Algeria, C Algeria; central Sahara, D south Mediterranean islands, E eastern Mediterranean region). Numbers after taxon names are linked to voucher specimens (see Online Resource 1). Map from http://www.d-maps.com
Table 1 Taxa and character information for the different regions of the dataset

\begin{tabular}{lrrrrrrr}
\hline & ETS & ITS & $n d h \mathrm{~F}$ & $r p l 32-t r n \mathrm{~L}$ & $\operatorname{trnH}-p s b \mathrm{~A}$ & $\operatorname{trn\mathrm {L}-trn\mathrm {F}}$ & All \\
\hline No. of taxa & 29 & 35 & 30 & 17 & 36 & 30 & 36 \\
No. of characters/aligned length & 553 & 805 & 2280 & 940 & 437 & 882 & 5897 \\
Variable characters & 77 & 120 & 76 & 14 & 34 & 28 & 349 \\
Informative characters & 50 & 61 & 34 & 8 & 10 & 11 & 174 \\
\hline
\end{tabular}


area reconstructions show the eastern Mediterranean region $(\mathrm{E} ; \mathrm{pp}=0.4)$ and Morocco and northwestern Algeria (B; $\mathrm{pp}=0.38$ ) as most probable ancestral area (Fig. 3, node 5). The crown age of Chiliadenus candicans, $C$. montanus, and C. iphionoides ( $\mathrm{PP}=1.0$; Fig. 3, node 6) is dated to $1.03 \mathrm{Ma}$ (0.56-1.64 Ma), with the eastern Mediterranean region (E) as most probable ancestral area $(\mathrm{pp}=0.98$; Fig. 3 , node 6$)$.

\section{Discussion}

Chiliadenus is here confirmed to be monophyletic ( $\mathrm{PP}=1.0)$, in agreement with earlier studies (Englund et al. 2009; Nylinder and Anderberg 2015), and the interrelationships of the different species resolved (Fig. 3). The position of Chiliadenus as sister to Dittrichia is recovered with high support $(\mathrm{PP}=1.0$; Fig. 3$)$. The estimated ages found in the present study fit well within the age of the Inuleae recovered by earlier studies (Nylinder et al. 2016). The ancestors of Chiliadenus and Dittrichia are estimated to have diverged around 5.45 Ma (3.25-8.55 Ma) somewhere in the area around continental southwestern Europe, Morocco, and northwestern Algeria (Fig. 3, node 1). The ancestral Chiliadenus then continued to evolve in northern Africa, whereas Dittrichia continued to evolve in Europe (Fig. 3). The Mediterranean basin was desiccated in the Miocene during what is referred to as the "Messinian salinity crisis" between 5.96 and 5.33 Ma ago, after the Strait of Gibraltar closed (Hsü et al. 1973; Krijgsman et al. 1999). Toward the end of this period, the Mediterranean basin would have been almost desiccated giving opportunities for plants and animals to colonize the land areas between Europe and North Africa, until it was once again submerged by the "Zanclean flood" ca. 5.33 Ma ago when the Atlantic waters found a way through the Strait of Gibraltar and refilled the Mediterranean basin (Garcia-Castellanos et al. 2009). It is possible that the desiccated Mediterranean may have provided opportunities for dispersal and range expansion for a widespread ancestor of Chiliadenus and Dittrichia until a vicariant event, possibly the Zanclean flood, led to the divergence of the ancestors of Dittrichia in continental Europe and Chiliadenus in northern Africa.

The Chiliadenus crown group is here determined to 2.29 Ma (1.37-3.58 Ma; Fig. 3, node 2). Ancestral area reconstructions show Morocco and northwestern Algeria as the most probable ancestral area for the Chiliadenus crown group and the area where most of the early divergences have occurred (Fig. 3). Chiliadenus has then later diverged and dispersed eastwards to the eastern Mediterranean region and to the south Mediterranean islands, as well as northward to continental southwestern Europe, and south to the central Sahara to its current distribution (Fig. 3).

A clade consisting of Chiliadenus antiatlanticus, $C$. saxatilis and C. sericeus $(\mathrm{PP}=1.0$; Fig. 3, node 3$)$, with a main distribution in Morocco, Algeria, and Spain started diversifying ca. $1.03 \mathrm{Ma}(0.42-1.91 \mathrm{Ma})$ and is sister to the rest of Chiliadenus. Chiliadenus sericeus, a species that has an isolated distribution in the central Sahara, far from the other species, is here placed as sister to $C$. saxatilis (Fig. 1a, b) with a wide distribution ranging from southern France to northern Morocco (Figs. 2, 3). There were, however, difficulties in sequencing DNA regions from the few available old specimens of Chiliadenus sericeus, only two out of six marker sequences could be generated, and its position must therefore be seen as somewhat uncertain. Chiliadenus antiatlanticus is found in the Anti-Atlas mountain range of Morocco. The ancestor of the group likely evolved in the area around Morocco and northwestern Algeria, with the current distributions of Chiliadenus saxatilis and C. sericeus the result of later dispersal and diversification (Fig. 3, node $3)$. The crown age of the rest of Chiliadenus is estimated to around 1.96 Ma (1.15-3.04 Ma; Fig. 3, node 4). Chiliadenus rupestris and $C$. hesperius, found in northern and southwestern Morocco (Fig. 2), are placed together although the node lacks support and are placed as sisters to the rest of the clade (Fig. 3). Chiliadenus bocconei and C. lopadusanus (Fig. 1d, e), endemic to the Maltese islands and Lampedusa island, respectively, are shown to be sisters ( $\mathrm{PP}=1.0$; Fig. 3, node 7 ) and estimated to have started diversifying ca. $0.4 \mathrm{Ma}$ (0.14-0.79 Ma). Their ancestor is estimated to have diverged from the ancestor of an eastern Mediterranean clade consisting of Chiliadenus candicans, C. montanus, and C. iphionoides around 1.58 Ma (0.9-2.49 Ma; Fig. 3, node 5), and to have spread to the south Mediterranean islands after that. Ancestral area reconstructions detect an eastward change in distribution from Morocco and northwestern Algeria to the eastern Mediterranean region sometime between 1.96 and $1.58 \mathrm{Ma}$ (Fig. 3). The ancestor of the two clades appears to have dispersed eastward, expanding its range and for some time being present in both areas, and later gone extinct in the west (Fig. 3, node 5). The ancestor of the eastern clade has then continued to expand its range eastwards and Chiliadenus candicans, $C$. montanus, and $C$. iphionoides all appear to have evolved in the eastern Mediterranean region (Fig. 3, node 6). Chiliadenus candicans, found in Libya, and C. montanus and C. iphionoides (Fig. 1c, f), with distributions in the Sinai Peninsula and in Israel, respectively, form a clade with an estimated crown age of $1.03 \mathrm{Ma}(0.56-1.64 \mathrm{Ma}$; Fig. 3, node 6) where C. candicans is placed as sister to the others.

The ancestor of Chiliadenus and Dittrichia is here estimated to have diverged around 5.45 Ma (3.25-8.55 Ma), whereas the Chiliadenus crown group is only dated to 2.29 Ma (1.37-3.58 Ma), showing a temporal gap of 3 million years (Fig. 3). The temporal gap (5.45-2.29 Ma) approximately spans from the beginning of the Messinian salinity crisis (5.96-5.33 Ma; Krijgsman et al. 1999) to the 
onset of the Mediterranean climate, a pattern detected in several other Mediterranean lineages as well (Fiz-Palacios and Valcárcel 2011, 2013). The Mediterranean climate, characterized by dry summers, with rainfall concentrated during the other seasons and with low temperatures during the winter, is thought to have originated around $3.2 \mathrm{Ma}$, with the summer draughts becoming stable around $2.8 \mathrm{Ma}$. Prior to that, moist climatic conditions (with rainy summers) would have prevailed (Suc 1984). The establishment of the Mediterranean climate at 3.2-2.8 Ma meant a significant environmental change, and the transition from moist climatic conditions to a climate with seasonal warm drought periods had a great impact on the flora. Another climatic change occurred around 2.3 Ma with the oldest xeric phase and the start of the Quaternary-type Mediterranean climatic fluctuations (Suc 1984). Fossil pollen shows a reduction in forest cover and an enlargement of steppe communities, indicating drier and milder climatic conditions at this time (Suc 1984). The diversification of Chiliadenus is dated to have occurred around the time of the climatic changes, and the evolution of the group may be connected to the climatic changes. At 2.29 Ma, around the time of the beginning of the Quaternary-type climatic fluctuations, the ancestral Chiliadenus had started to evolve into two genetically distinct groups, where one continued to evolve and spread in Morocco and Algeria, and later in southern continental Europe, eventually resulting in $C$. saxatilis, $C$. sericeus and $C$. antiatlanticus (Fig. 3). The other group that started to diversify around $1.96 \mathrm{Ma}$ spread and diversified with time into a western and an eastern group at 1.77 and $1.58 \mathrm{Ma}$, respectively, where the western group eventually evolved into Chiliadenus rupestris and C. hesperius (Fig. 3). The eastern group spread and diversified further into an island clade representing Chiliadenus lopadusanus and C. bocconei and an eastern Mediterranean mainland clade, which eventually evolved into C. candicans, C. montanus and C. iphionoides (Fig. 3).

\section{Conclusions}

Ancestral Chiliadenus diverged from its sister Dittrichia around 5.45 Ma, possibly as an effect of the Messinian salinity crisis and subsequent Zanclean flooding of the Mediterranean basin. The Chiliadenus crown group likely evolved and started to diversify in the area around Morocco and northwestern Algeria. The different taxa have since spread and continued to diversify around the Mediterranean region eventually resulting in the current diversity and distribution of the genus. The diversification of Chiliadenus seems to coincide with the onset of the Mediterranean climate becoming increasingly dryer, and the diversification of the different species groups may be connected to the climatic changes.
Acknowledgements The authors are grateful to the Institut Botànic de Barcelona (BC), the Hebrew University (HUJ), the Université Montpellier (MPU), the Muséum National d'Historie Naturelle (P) and the Naturhistorisches Museum Wien (W) herbaria for providing loans and access to the collections. We would also like to thank Rikard Anderberg, Markus Englund, Ori Fragman-Sapir and Stephen Mifsud for allowing us to use their photos; the staff at the Molecular Systematics Laboratory at the Swedish Museum of Natural History for technical assistance; and the two anonymous reviewers for many valuable comments on the manuscript.

\section{Compliance with ethical standards}

Conflict of interest The authors declare that they have no conflict of interest.

Open Access This article is distributed under the terms of the Creative Commons Attribution 4.0 International License (http://creativeco mmons.org/licenses/by/4.0/), which permits unrestricted use, distribution, and reproduction in any medium, provided you give appropriate credit to the original author(s) and the source, provide a link to the Creative Commons license, and indicate if changes were made.

\section{Information on Electronic Supplementary Mate- rial}

Online Resource 1. Voucher information and GenBank accession numbers.

Online Resource 2. DNA sequence alignments in nexus format.

\section{References}

Akaike H (1973) Information theory and an extension of the maximum likelihood principle. In: Petriv BN, Csáki F (eds) Second international symposium on information theory, Tsahkadzor, Armenia, 2-8 September 1971. Akadémiai Kiadó, Budapest, pp 267-281

Anderberg AA (2012) Ray-florets in Chiliadenus (Asteraceae-Inuleae), discovered: An epigenetic phenomenon? Compos Newslett 50:40-45

Anderberg AA, Swenson U (2003) Evolutionary lineages in Sapotaceae (Ericales): a cladistics analysis based on $n h d \mathrm{~F}$ sequence data. Int J Pl Sci 164:763-773

Baldwin BG, Markos S (1998) Phylogenetic utility of the external transcribed spacer (ETS) of 18S-26S rDNA: congruence of ETS and ITS trees of Calycadenia (Compositae). Molec Phylogen Evol 10:449-463

Bonanno G, Veneziano V (2016) New insights into the distribution patterns of Mediterranean insular endemic plants: the Sicilian islands' group. Flora 224:230-243. https://doi.org/10.1016/j.flora .2016.09.001

Brullo S (1979) Taxonomic and nomenclatural notes on the genera Jasonia Cass. and Chiliadenus Cass. (Compositae). Webbia 34:289-308

Darriba D, Taboada GL, Doallo R, Posada D (2012) jModelTest 2: more models, new heuristics and parallel computing. Nature Methods 9:772. https://doi.org/10.1038/nmeth.2109

Drummond AJ, Suchard MA, Xie D, Rambaut A (2012) Bayesian phylogenetics with BEAUti and the BEAST 1.7. Molec Biol Evol 29:1969-1973. https://doi.org/10.1093/molbev/mss075

Edgar RC (2004) MUSCLE: multiple sequence alignment with high accuracy and high throughput. Nucl Acids Res 32(5):1792-1797. https://doi.org/10.1093/nar/gkh340 
Eldenäs P, Källersjö M, Anderberg AA (1999) Phylogenetic placement and circumscription of tribes Inuleae s. str. and Plucheeae (Asteraceae): evidence from sequences of chloroplast gene ndhF. Molec Phylogen Evol 13:50-58

Englund M, Pornpongrungrueng P, Gustafsson MHG, Anderberg AA (2009) Phylogenetic relationships and generic limitation in Inuleae subtribe Inulinae (Asteraceae) based on ITS and cpDNA sequence data. Cladistics 25:319-352. https://doi.org/10.111 1/j.1096-0031.2009.00256.x

Fiz-Palacios O, Valcárcel V (2011) Imbalanced diversification of two Mediterranean sister genera (Bellis \& Bellidium, Asteraceae) within the same time frame. Pl Syst Evol 295:109-118. https:// doi.org/10.1007/s00606-011-0468-5

Fiz-Palacios O, Valcárcel V (2013) From Messinian crisis to Mediterranean climate: a temporal gap of diversification recovered from multiple plant phylogenies. Perspect Pl Ecol Evol Syst 15:130 137. https://doi.org/10.1016/j.ppees.2013.02.002

Garcia-Castellanos D, Estrada F, Jiménez-Munt I, Gorini C, Fernàndes M, Vergés J, De Vicente R (2009) Catastrophic flood of the Mediterranean after the Messinian salinity crisis. Nature 462:778-781. https://doi.org/10.1038/nature08555

Gernhard T (2008) The conditioned reconstructed process. J Theor Biol 253:769-778. https://doi.org/10.1016/j.tbi.2008.04.005

Gómiz F (2000) Notas sobre flora de Marruecos. II. Anal Jard Bot Madrid 58:199-200

Greuter W (1991) Botanical diversity, endemism, rarity, and extinction in the Mediterranean area: an analysis based on the published volumes of Med-Checklist. Bot Chron 10:63-79

Hall TA (1999) BioEdit: a user-friendly biological sequence alignment editor and analysis program for Windows 95/98/NT. Nucl Acids Symp Ser 41:95-98

Hamilton MB (1999) Four primer pairs for the amplification of chloroplast intergenic regions with intraspecific variation. Molec Ecol 8:521-523

Howis S, Barker NP, Mucina L (2009) Globally grown but poorly known: species limits and biogeography of Gazania Gaertn. (Asteraceae) inferred from chloroplast and nuclear DNA sequence data. Taxon 58:871-882

Hsü KJ, Ryan WBF, Cita MB (1973) Late Miocene desiccation of the Mediterranean. Nature 242:240-244

Huelsenbeck JP, Ronquist FR (2001) MrBayes: Bayesian inference of phylogenetic trees. Bioinformatics 17:754-755

Källersjö M, Bergqvist G, Anderberg AA (2000) Generic realignment in primuloid families of the ericales s.l.: a phylogenetic analysis based on DNA sequences from three chloroplast genes and morphology. Amer J Bot 87:1325-1341

Kay KM, Whittall JB, Hodges SA (2006) A survey of nuclear ribosomal internal transcribed spacer substitution rates across angiosperms: an approximate molecular clock with life history effects. BMC Evol Biol 6:36. https://doi.org/10.1186/1471-2148-6-36

Kim K-J, Jansen RK (1995) NdhF sequence evolution and the major clades in the sunflower family. Proc Natl Acad Sci USA 92:10379-10383

Krijgsman W, Hilgen FJ, Raffi I, Sierro FJ, Wilson DS (1999) Chronology, causes and progression of the Messinian salinity crisis. Nature 400:652-655
Lancaster LT (2010) Molecular evolutionary rates predict both extinction and speciation in temperate angiosperm lineages. BMC Evol Biol 10:162. https://doi.org/10.1186/1471-2148-10-162

Larsson A (2014) AliView: a fast and lightweight alignment viewer and editor for large data sets. Bioinformatics 30:3276-3278. https:// doi.org/10.1093/bioinformatics/btu531

Markos S, Baldwin BG (2001) Higher-level relationships and major lineages of Lessingia (Compositae, Astereae) based on nuclear rDNA internal and external transcribed spacer (ITS and ETS) sequences. Syst Bot 26:168-183

Nylinder S, Anderberg AA (2015) Phylogeny of the Inuleae (Asteraceae) with special emphasis on the Inuleae-Plucheinae. Taxon 64:110-130. https://doi.org/10.12705/641.22

Nylinder S, Cronholm B, de Lange PJ, Walsh N, Anderberg AA (2013) Species tree phylogeny and character evolution in the genus Centipeda (Asteraceae): evidence from DNA sequences from coding and non-coding loci from the plastid and nuclear genomes. Molec Phylogen Evol 68:239-250. https://doi.org/10.1016/j. ympev.2013.03.020

Nylinder S, Lemey P, de Bruyn M, Suchard MA, Pfeil BE, Walsh N, Anderberg AA (2014) On the biogeography of Centipeda: a species-tree diffusion approach. Syst Biol 63:178-191. https://doi. org/10.1093/systbio/syt102

Nylinder S, Razafimandimbison SG, Anderberg A (2016) From the Namib around the world: biogeography of the Inuleae-Plucheinae (Asteraceae). J Biogeogr 43:1705-1716. https://doi.org/10.1111/ jbi.12764

Olmstead RG, Sweere JA (1994) Combining data in phylogenetic systematics: an empirical approach using three molecular data sets in the Solanaceae. Syst Biol 43:467-481

Rambaut A (2009) FigTree v.1.3.1. Available at: http://tree.bio.ac.uk/ software/figtree/

Rambaut A, Drummond, AJ (2009) Tracer, v.1.5. Available at: http:// beast.bio.ed.ac.uk/Tracer

Rydin C, Raunsgaard Pedersen K, Friis EM (2004) On the evolutionary history of Ephedra: cretaceous fossils and extant molecules. Proc Nat Acad Sci USA 101:16571-16576

Schmidt GJ, Schilling EE (2000) Phylogeny and biogeography of Eupatorium (Asteraceae: Eupatorieae) based on nuclear ITS sequence data. Amer J Bot 87:716-726

Shaw J, Lickey EB, Schilling EE, Small RL (2007) Comparison of whole chloroplast genome sequences to choose noncoding regions for phylogenetic studies in Angiosperms: the tortoise and the hare III. Amer J Bot 94:275-288. https://doi.org/10.3732/ajb.94.3.275

Staden R (1996) The Staden sequence analysis package. Mol Biotechnol 5:233-241

Suc J-P (1984) Origin and evolution of the Mediterranean vegetation and climate in Europe. Nature 307:429-432

Taberlet P, Gielly L, Pautou G, Bouvet J (1991) Universal primers for amplification of three non-coding regions of chloroplast DNA. Pl Molec Biol 17:1105-1109

Thompson JD (2005) Plant evolution in the Mediterranean. Oxford University Press, Oxford 